\title{
Laju Pertumbuhan Kerang Abalon Haliotis squamata Melalui Budidaya IMTA (Integrated Multi Trophic Aquaculture) di Pantai Geger, Nusa Dua, Kabupaten Badung, Provinsi Bali
}

\author{
Heny Hayati a*, I Gusti Ngurah Putra Dirgayusa a, Ni Luh Putu Ria Puspitha a \\ a Program Studi Ilmu Kelautan, Fakultas Kelautan dan Perikanan, Universitas Udayana, Kampus UNUD Bukit Jimbaran, Bali 80361, Indonesia \\ *Penulis koresponden. Tel.: +62-8123-7301-933 \\ Alamat e-mail: hennyhayati734@yahoo.co.id
}

Diterima (received) 19 Juli 2017; disetujui (accepted) 4 November 2017; tersedia secara online (available online) 5 November 2017

\begin{abstract}
Abalone is an important non fishery commodity that has high potential value to be developed. Abalone culture still faces some problems, such as, relatively slow growth rate, low survival rate and causing environmental pollution. One of the efforts to tackle the problems, is applying the culture system that is environmental friendly, such as IMTA (Integrated Multitrophic Aquaculture). This research aims to identify the growth rate and survival rate of the abalone (Haliotis squamata) and the suitability of chemical and physical environment parameter supporting the integration culture of abalone and seaweed (Gracilaria sp) on different stocking density at Geger beach, Nusa Dua, Bali. This research was performed in 45 days using a complete randomized design method that consist of three treatments and three repetition. The result showed that the highet growth rate was on treat ment $\mathrm{T} 3$ which consisted of abalone (Haliotis squamata) 40 individu and 10 bunches of seaweed (Gracilaria sp) 100 grams weight/each individu (0.76\%/day), then It followed by T2 treatment that was integrated with 10 bunches of seaweed 50 grams (0.71\%/day). The lowest growth rate observed on treatment $\mathrm{T} 1$ (control/monoculture) which consisted of 40 individu abalone (Haliotis squamata) $(0.59 \% /$ day). The highest survival rate found on treatment $\mathrm{T} 2(97.5 \%)$ and followed by treatment $\mathrm{T} 1$ as control $(94.5 \%)$, while the lowest number was found on treatment T3 $(83.3 \%)$. Physical chemical water quality parameters showed that It supported the growth of both, abalone (Haliotis squamata) and seaweed (Gracilaria sp.) at Geger Beach, Nusa Dua, Badung Regency, Bali Province.
\end{abstract}

Keywords: Geger Beach; Gracilaria sp; growth rate; H. squamata; IMTA

\begin{abstract}
Abstrak
Abalon merupakan komoditas non perikanan yang memiliki potensi tinggi untuk dikembangkan. Budidaya abalon masih menemui beberapa permasalahan, seperti laju pertumbuhan yang relatif lambat, tingkat kelulushidupan yang rendah dan pencemaran pada lingkungan perairan. Salah satu upaya adalah dengan menerapkan sistem budidaya yang ramah lingkungan yaitu menggunakan sistem budidaya IMTA (Integrated Multi Trophic Aquaculture). Penelitian ini bertujuan untuk mengetahui laju pertumbuhan dan kelulushidupan abalon (Haliotis squamata) dan mengetahui kesesuaian parameter lingkungan kimia dan fisika mendukung budidaya terintegrasi terhadap pertumbuhan abalon (Haliotis squamata) dan rumput laut (Gracilaria sp) pada berat tanam yang berbeda di pantai Geger, Nusa Dua, Bali. Penelitian ini dilaksanakan selama 45 hari dengan menggunakan metode rancangan acak lengkap yang terdiri dari tiga perlakuan dan tiga kali ulangan. Hasil penelitian menunjukkan bahwa nilai pertumbuhan tertinggi terdapat pada perlakuan T3 yang terdiri dari 40 individu abalon (Haliotis squamata) dan 10 ikat rumput laut (Gracilaria sp) 100 gram/masing-masing individu (0,76\%/hari), kemudian diikuti oleh perlakuan T2 yang diintegrasikan dengan $10 \mathrm{ikat}$ rumput laut (Gracilaria sp) 50 gram (0,71\%/hari). Laju pertumbuhan terendah yang diamati pada perlakuan $\mathrm{T} 1$ (kontrol/monokultur) yang terdiri dari 40 individu abalon (Haliotis squamata) $(0,59 \% /$ hari). Kelulushidupan tertinggi terdapat pada perlakuan T2 (97,5\%) dan diikuti perlakuan T1 sebagai kontrol yaitu (94,5\%), sedangkan jumlah terendah terdapat pada perlakuan T3 (83,3\%). Parameter kualitas perairan fisika dan parameter kualitas perairan kimia mendukung budidaya terintegrasi terhadap pertumbuhan kerang abalon (Haliotis squamata) dan rumput laut (Gracilaria sp.) di Pantai Geger, Nusa Dua, Kabupaten Badung, Provinsi Bali.
\end{abstract}

Kata Kunci: Gracilaria sp; H.squamata; IMTA; laju pertumbuhan; Pantai Geger 


\section{Pendahuluan}

Abalon (Haliotis squamata) yang dikenal dengan kerang mata tujuh merupakan komoditas non perikanan dunia yang tergolong dalam kelas Gastropoda dan hewan pemakan tumbuhtumbuhan. Menurut Setyono (2004) abalon yang ditemukan di Indonesia terdiri dari tujuh spesies yaitu $H$. asinina, $H$. varia, $H$. squamata, H.ovina, $H$. glabra, H. planata, dan H. crebrisculpta. Dari ketujuh spesies yang ditemukan di Indonesia, abalon Haliotis squamata memiliki potensi untuk dibudidayakan. Kerang mata tujuh ini memiliki potensi yang cukup baik untuk dikembangkan khususnya jenis abalon $H$. squamata memiliki cita rasa daging yang khas dan sebagai salah satu komoditas yang tergolong ekspor. Leighton (2008) menyatakan bahwa komoditas abalon di Cina, Taiwan dan Korea semakin meningkat. Melihat tingginya permintaan ekspor akan abalon, maka komoditas abalon di Indonesia layak untuk dikembangkan secara berkelanjutan sebagai spesies unggulan dalam kegiatan budidaya laut.

Budidaya abalon masih menemui beberapa permasalahan, seperti laju pertumbuhan yang relatif lambat dan pencemaran pada lingkungan perairan yang disebabkan oleh buangan pakan yang tidak terkonsumsi. Menurut Soelistyowati et al., (2013) kerang abalon memiliki laju pertumbuhan relatif dan kelangsungan hidup rendah. Kebutuhan akan abalon semakin meningkat, sehingga dapat mendorong usaha penangkapan abalon di alam secara intensif. Berdasarkan penelitian, data penangkapan kerang abalon di dunia dari tahun 1970 sampai tahun 2008 dengan nilai $20.000 \mathrm{mt}$ menjadi $9.000 \mathrm{mt}$ sehingga menunjukan penurunan jumlah penangkapan di alam (Cook dan Gordon 2010; Gordon and Cook, 2013). Permasalahan tersebut merupakan kendala yang perlu diselesaikan.

Salah satu upaya adalah dengan menerapkan sistem budidaya yang ramah lingkungan yaitu menggunakan sistem budidaya IMTA (Integrated Multi Trophic Aquaculture). Konsep budidaya dengan menggunakan penerapan sistem IMTA merupakan suatu konsep yang dapat dikembangkan untuk menumbuhkan minimal dua organisme yang berbeda atau lebih seperti mengintegrasikan budidaya ikan atau udang dengan kekerangan dan rumput laut (Setyowati et al., 2013). Dalam penerapan sistem budidaya IMTA, sisa pakan dari ikan dan limbah organik akan dimanfaatkan oleh kekerangan dan rumput laut akan memanfaatkan perairannya yang kaya akan nutrien untuk pertumbuhannya sehingga terjadinya keseimbangan ekosistem (Aliah, 2012).

Penerapan sistem budidaya IMTA secara berkelanjutan dapat membantu dalam mengurangi dampak lingkungan. Sistem IMTA memiliki fungsi yang berbeda di setiap spesies seperti, karnivora, filter feeder, detritifor dan penyerap limbah inorganik. Prinsip dari sistem budidaya IMTA yaitu mendaur ulang limbah dari kegiatan budidaya yang menjadi sumber energi dan nitrogen oleh spesies utama, sehingga menghasilkan suatu produk yang dapat mengurangi dampak lingkungan dan dapat di panen (Ren et al., 2012). Sebagai contoh dengan mengintegrsikan dua spesies yaitu abalon $H$. squamata memiliki peran sebagai filter feeder dan rumput laut Gracilaria sp. memiliki peran sebagai biofilter, dari kedua sepesies tersebut memiliki potensi nilai ekonomis yang tinggi.

Penelitian kali ini mengenai pengintegrasian kerang abalon $H$. squamata dan rumput laut jenis Gracilaria sp. dilaksanakan di Kawasan Pantai Geger, Desa Adat Peminge, Sawangan, Nusa Dua, Kabupaten Badung, Provinsi Bali. Kawasan Pantai Geger merupakan daerah pariwisata dan terdapat budidaya rumput laut yang dikelola oleh warga setempat. Kondisi perairan di Pantai Geger ditinjau dari tipe habitat kerang abalon yang memiliki tipe substrat berupa karang berpasir dan berbatu yang ditumbuhi rumput laut salah satunya jenis rumput laut Gracilaria sp. Rumput laut Gracilaria sp dapat dibudidayakan diperairan laut maupun tambak. Gracilaria sp juga dimanfaatkan sebagai pakan kerang abalon. Selama ini, penelitian mengenai laju pertumbuhan kerang abalon $H$. squamata yang diintegrasikan dengan rumput laut Gracilaria sp. belum pernah ada yang melakukan penelitian tersebut di Pantai Geger, sehingga penelitian ini penting untuk dilakukan.

Maksud dan tujuan dari penelitian ini yaitu untuk mengetahui laju pertumbuhan kerang abalon H. squamata, kelulushidupan kerang abalon H. squamata ketika diintegrasikan bersama dengan rumput laut Gracilaria sp. pada berat tanam yang berbeda dan pada budidaya secara monokultur di Pantai Geger serta mengetahui kesesuaian parameter lingkungan kimia dan fisika mendukung budidaya terintegrasi terhadap pertumbuhan kerang abalon $H$. squamata dan 


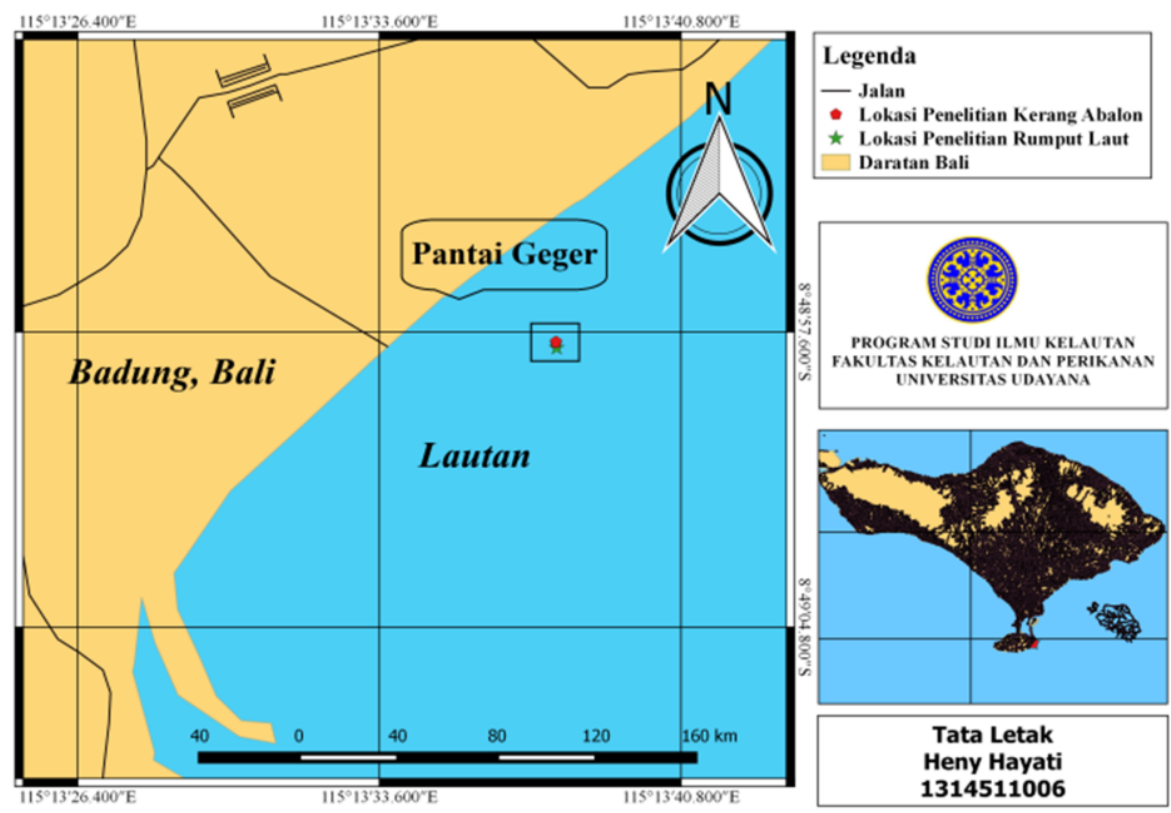

Gambar 1. Peta Lokasi Penelitian

rumput laut Gracilaria sp. di Pantai Geger, Nusa Dua, Kabupaten Badung, Provinsi Bali.

\section{Metode Penelitian}

\subsection{Waktu dan Lokasi Penelitian}

Penelitian ini dilaksanakan selama 45 hari, yaitu pada tanggal 25 Februari sampai dengan 9 April 2017. Penelitian berlokasi di Pantai Geger, Nusa Dua, Kabupaten Badung, Provinsi Bali. Peta lokasi penelitian dapat dilihat pada (Gambar 1).

\subsection{Rancangan Penelitian}

Penelitian ini menggunakan metode Rancangan Acak Lengkap (RAL) yang terdiri dari tiga perlakuan dengan masing-masing perlakuan terdapat tiga kali ulangan. Perlakuan berupa kerang abalon $H$. squamata yang diintegrasikan dengan padat tanam rumput laut Gracilaria sp. yang berbeda. Hewan uji ditebar disetiap keranjang dengan 40 individu abalon. Pakan yang diberikan yaitu rumput laut Gracilaria sp. yang berasal dari alam atau Pantai Geger dan sistem budidaya IMTA. Berikut rancangan percobaan ditampilkan pada Tabel 1. Adapun T1 adalah kerang abalon $H$. squamata sebagai kontrol (40 individu), T2 adalah kerang abalon H. squamata (40 individu) dan rumput laut dengan berat (50 gram), dan T3 adalah kerang abalon $H$. squamata (40 individu) dan rumput laut dengan berat (100 gram)

Tabel 1.

Rancangan Percobaan

\begin{tabular}{cccc}
\hline \multirow{2}{*}{ Ulangan } & \multicolumn{3}{c}{ Perlakuan } \\
\cline { 2 - 4 } & $\mathrm{T} 1$ (Kontrol) & $\mathrm{T} 2$ & $\mathrm{~T} 3$ \\
\hline 1 & $\mathrm{~T}_{11}$ & $\mathrm{~T}_{21}$ & $\mathrm{~T}_{31}$ \\
2 & $\mathrm{~T}_{12}$ & $\mathrm{~T}_{22}$ & $\mathrm{~T}_{32}$ \\
3 & $\mathrm{~T}_{13}$ & $\mathrm{~T}_{23}$ & $\mathrm{~T}_{33}$ \\
\hline
\end{tabular}

\subsection{Pengumpulan Data}

Hewan uji yang digunakan adalah kerang abalon H. squamata yang berasal dari Balai Besar Penelitian dan Pengembangan Budidaya Laut (BBPPBL), Gondol-Bali. Jumlah total kerang abalon $H$. squamata yang digunakan sebanyak 360 individu. Pemilihan kerang abalon $H$. squamata umumnya memiliki ukuran panjang cangkang yang seragam dengan kisaran ukuran $4 \mathrm{~cm}$ dan kerang abalon $H$. squamata dalam kondisi yang sehat.

Rumput laut yang digunakan yaitu jenis Gracilaria sp. Bibit rumput laut Gracilaria sp. berasal dari alam yaitu Pantai Geger, Nusa Dua, Bali. Pemilihan rumput laut umumnya memiliki bibit yang muda, segar dan bersih. Bibit rumput 
laut yang digunakan harus ditimbang terlebih dahulu agar sesuai dengan berat yang telah ditetapkan pada perlakuan. Selanjutnya tahap persiapan wadah atau keranjang penelitian, tahapan ini merupakan tahapan yang menentukan tingkat keberhasilan dalam kegiatan budidaya dan dilanjutkan dengan pembuatan kontruksi didasar laut. Kontruksi budidaya didesain sehingga membentuk kontruksi yang layak digunakan. Kontruksi budidaya kerang abalon $H$. squamata dan rumput laut Gracilaria sp. pada penelitian ini terdapat dua jenis kontruksi, yaitu kontruksi budidaya secara monokultur (perlakuan T1 sebagai kontrol) dan budidaya IMTA (perlakuan T2 dan T3 yang diintegrasikan dengan rumput laut).

Kontruksi budidaya secara monokultur didesain secara menyendiri atau tidak secara terintegrasi bersama rumput laut Gracilaria sp. dan untuk kontruksi budidaya IMTA didesain secara bersamaan dengan rumput laut Gracilaria sp. Tempat pemeliharaan kerang abalon dengan menggunakan keranjang buah yang berukuran panjang $48,5 \mathrm{~cm} \times 32 \mathrm{~cm} \times 15 \mathrm{~cm}$. Ukuran keranjang yang digunakan perlu dipertimbangkan untuk menentukan padat penebaran dan ukuran benih kerang abalon. Keranjang buah di lapiskan struktur bambu supaya kerang abalon yang berada didalam keranjang tidak mudah lepas, karena benih kerang abalon yang digunakan berukuran $4 \mathrm{~cm}$. Sedangkan untuk kontruksi rumput laut diletakkan diatas keranjang kerang abalon dengan cara dilingkari pada kontruksi kerang abalon. Bahan yang digunakan untuk penanaman rumput laut yaitu dengan menggunakan tali ris yang berukuran $2 \mathrm{~m}$ dan jaring yang berukuran $25 \mathrm{~cm}$. Jarak dari keranjang ke tali ris yaitu $5 \mathrm{~cm}$. Kontruksi budidaya secara monokultur dan IMTA disajikan pada Gambar 2.

Kerang abalon $H$. squamata dipelihara pada wadah/keranjang yang telah disiapkan. Benih kerang abalon sebelum diberikan perlakuan dan diintegrasikan dengan rumput laut Gracilaria sp. terlebih dahulu diaklimatisasi selama 24 jam didalam wadah/keranjang yang telah disiapkan pada kontruksi, supaya benih kerang abalon dapat beradaptasi terhadap lingkungan baru yang ditempati. Sampling pertumbuhan berat kerang abalon dilakukan dua minggu sekali dimulai pada awal penelitian sampai akhir penelitian. Pengukuran berat kerang abalon dengan menggunakan timbangan digital dengan ketelitian 0,01 gram. Selama pemeliharaan kerang abalon $H$. squamata diberi pakan berupa rumput laut Gracilaria sp secukupnya dan pakan diberikan tiga hari sekali.

Pengukuran parameter kualitas perairan seperti kecerahan dan kedalaman dilakukan pada awal penelitian, untuk pengukuran suhu dilakukan setiap tiga hari sekali bersamaan dengan pemberian pakan kerang abalon $H$. squamata. Pengambilan sampel air nitrat dan fosfat dilakukan pada awal dan akhir penelitian. Pengukuran salinitas dan derajat keasaman $(\mathrm{pH})$ dilakukan pada waku yang berbeda sedangkang untuk oksigen terlarut (DO) dilakukan setiap pagi hari dan pengamatan dilakukan pada dua minggu sekali bersamaan dengan sampling kerang abalon dan secara in situ.
Mono - Culture

T1 (Kontrol)

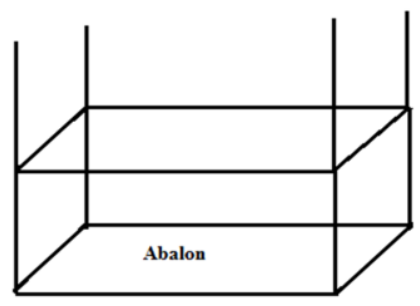

IMTA

T2 (Kerang Abalon + RL 50 gram)

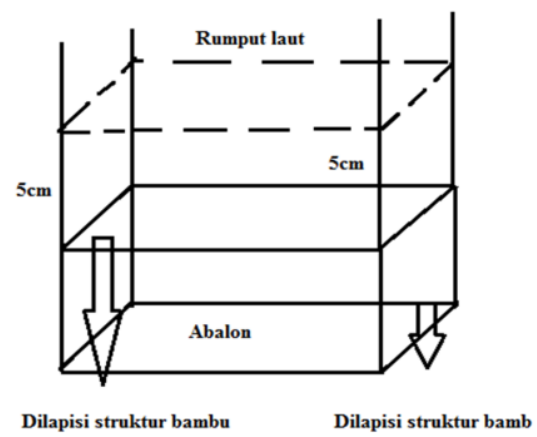

IMTA

T3 (Kerang Abalon + RL 100 gran

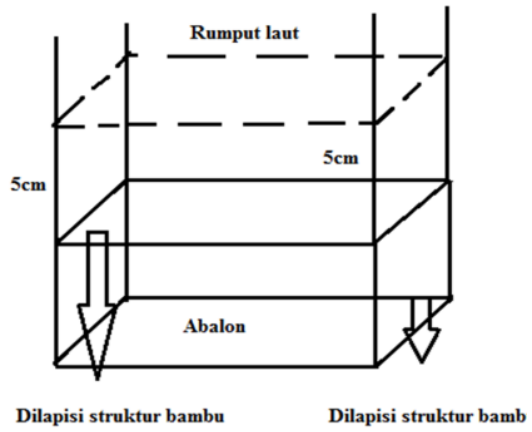

Gambar 2. Kontruksi pembudidayaan kerang abalon dan rumput laut secara IMTA dan monokultur. 


\subsection{Analisis Data}

\subsubsection{Analisis ANOVA}

Penelitian ini terdiri dari tiga perlakuan dan tiga kali ulangan. Rancangan yang digunakan yaitu Rancangan Acak Lengkap (RAL) dengan konsentrasi yang berbeda sebagai perlakuan. Data pertumbuhan berat badan kerang abalon $H$. squamata yang diperoleh terlebih dahulu di analisis menggunakan Levene's Test untuk mengetahui data berat badan kerang abalon terdistribusi normal, jika data terdistribusi dengan normal maka dilakukan uji statistik One Way ANOVA yang fungsinya untuk mengetahui apakah data berat badan kerang abalon berpengaruh terhadap perlakuan pertumbuhan dan jika data berat tidak terdistribusi dengan normal maka dilakukan uji statistik secara Non Parametrik. Adapun proses perhitungannya dilakukan dengan bantuan software SPSS versi 23.0.

\subsubsection{Laju Pertumbuhan Spesifik (SGR)}

Perhitungan laju pertumbuhan spesifik kerang abalon dilakukan dengan bantuan Microsoft Excel 2010. Laju pertumbuhan spesifik dihitung menggunakan rumus dalam Syahlun dan Ruslaini (2013) ditunjukan pada persamaan 1.

$\mathrm{SGR}=\frac{\operatorname{LnW}_{\mathrm{t}^{-}}-\operatorname{LnW}_{0}}{\mathrm{t}} \times 100 \%$

dimana, SGR adalah laju pertumbuhan spesifik (\%), LnWt adalah berat hewan uji pada akhir percobaan (g), LnWo adalah berat hewan uji pada awal percobaan $(\mathrm{g})$, dan $\mathrm{t}$ adalah interval waktu percobaan (hari).

\subsubsection{Kelulusan Kerang Abalon (\%)}

Kelulushidupan benih kerang abalon dihitung pada awal penebaran dan akhir penelitian. Rumus yang digunakan menurut Yustianti et al., (2013) ditunjukan pada persamaan 2 .

$\mathrm{SR}=\frac{\mathrm{Nt}}{\mathrm{No}} \times 100 \%$

dimana, SR adalah kelulushidupan kerang abalon (\%), No adalah jumlah kerang abalon pada awal penelitian (ekor), dan $\mathrm{Nt}$ adalah jumlah kerang abalon pada akhir penelitian.

\subsection{Parameter Lingkungan}

\subsubsection{Kecerahan Perairan}

Pengukuran kecerahan perairan menggunakan secchi disk. Dapat dihitung dengan menggunakan rumus Effendi, (2003) ditunjukan pada persamaan 3.

$\mathrm{P}=\frac{(\mathrm{x}+\mathrm{y})}{2}$

dimana, $\mathrm{P}$ adalah kecerahan, $\mathrm{x}$ adalah jarak secchi disk masih terlihat dan y adalah tidak terlihat (\%).

\subsubsection{Nutrien (nitrat dan fosfat) Pada Perairan}

Analisis nitrat dan fosfat di perairan dilakukan di Laboratorium Kesehatan Provinsi Bali dengan metode brusin untuk menganalisis nitrat (SNI M53-1990-03) dan untuk menganalisis fosfat menggunakan metode amm molyddat. Sampel air yang diambil sebanyak 1,5 liter.

\section{Hasil dan Pembahasan}

\subsection{Kualitas Perairan}

Hasil pengukuran kualitas perairan parameter fisika dan parameter kimia pada lokasi penelitian disajikan pada Tabel 2.

Tabel 2

Pengukuran Kualitas Perairan di Lokasi Penelitian.

\begin{tabular}{clcc}
\hline No & \multicolumn{1}{c}{ Parameter } & Satuan & Nilai \\
\hline 1 & Suhu & ${ }^{\circ} \mathrm{C}$ & $22,7-31,5$ \\
2 & Salinitas & $\mathrm{ppt}$ & $33-35$ \\
3 & Oksigen Terlarut (DO) & $\mathrm{mg} / 1$ & $5,2-5-57$ \\
4 & Derajat Keasaman $(\mathrm{Ph})$ & - & $8,14-8.17$ \\
5 & Kedalaman & $\mathrm{m}$ & $40-80 \mathrm{~cm}$ \\
6 & Kecepatan Arus & $\mathrm{m} / \mathrm{s}$ & 0,05 \\
\hline
\end{tabular}

Tabel 3

Analisis Nitrat dan Fosfat di Lokasi Penelitian.

\begin{tabular}{lcccc}
\hline Parameter & \multicolumn{2}{c}{ Kontruksi 1} & \multicolumn{2}{c}{ Kontruksi 2} \\
\cline { 2 - 5 } Lingkungan & Awal & Akhir & Awal & Akhir \\
\hline Nirat $(\mathrm{mg} / \mathrm{l})$ & $<0,01$ & 0,642 & $<0,01$ & 0,711 \\
Fosfat $(\mathrm{mg} / \mathrm{l})$ & 0,212 & 0,054 & 0,611 & 0,1524 \\
\hline
\end{tabular}

Berdasarkan hasil pengukuran kualitas perairan selama pemeliharaan kerang abalon dan 
rumput laut didapatkan hasil pengukuran suhu yaitu berkisar $27,3^{\circ} \mathrm{C}$ dan $31,5^{\circ} \mathrm{C}$. Hal tersebut berada diluar kisaran optimum untuk pertumbuhan kerang abalon dan juga rumput laut. Leighton (2008), menyatakan bahwa kisaran suhu yang cocok untuk keberlangsungan hidup kerang abalon adalah $28-30^{\circ} \mathrm{C}$ dan kisaran suhu tersebut juga sesuai untuk keberlangsungan hidup rumput laut Gracilaria sp. Kisaran suhu untuk buidaya rumput laut yaitu berkisar antara $26-30^{\circ} \mathrm{C}$ (Mudeng et al., 2015).

Hasil pengukuran salinitas selama pemeliharaan kerang abalon $H$. squamata dan rumput laut Gracilaria sp. tergolong optimal untuk pemeliharaan kerang abalon $H$. squamata yaitu berkisar antara 33-35ppt. Kisaran tersebut tidak sesuai untuk pertumbuhan rumput laut karena berada diatas kisaran optimum. Susanto et al., (2010), menyatakan bahwa kisaran salinitas yang optimal untuk pemeliharaan kerang abalon yaitu berkisar antara 30-35ppt, sedangkan menurut Guo et al., (2014), kisaran optimum untuk pertumbuhan rumput laut Gracilaria yaitu berkisar 25-33ppt dan memilliki toleransi yang tinggi terhadap perubahan salinitas yaitu berkisar 1040ppt.

Kadar oksigen terlarut (DO) selama pemeliharaan kerang abalon dan rumput laut yaitu berkisar antara 5,3 - 5,7 mg/l. Kisaran oksigen terlarut tersebut merupakan kisaran yang masih layak untuk kelangsungan hidup kerang abalon dan juga rumput laut. Kerang abalon pada umumnya menyukai daerah perairan yang mengandung oksigen terlarut yang tinggi. Kadar oksigen terlarut yang cocok untuk pemeliharaan kerang abalon adalah lebih besar dari $5 \mathrm{mg} / \mathrm{l}$ (Nurfajrie et al., 2014). Dahlia et al., (2015) menyatakan bahwa nilai oksigen terlarut untuk rumput laut yaitu berkisar lebih besar dari $5 \mathrm{mg} / \mathrm{l}$.

Kisaran derajat keasaman $(\mathrm{pH})$ selama pemeliharaan kerang abalon dan rumput laut yaitu berkisar antara $8,14-8,17$. Kisaran $\mathrm{pH}$ yang diperoleh masih tergolong optimal untuk pertumbuhan kerang abalon dan rumput laut. Cook dan Gordon (2010) menyatakan bahwa kisaran $\mathrm{pH}$ yang baik untuk pertumbuhan yuwana abalon yaitu berkisar antara 7,8-8,5 sehingga dengan demikian $\mathrm{pH}$ yang diperoleh dengan kisaran tersebut tergolong ideal. Ain et al., (2014) menyatakan bahwa hampit seluruth makro alga menyukai kisaran $\mathrm{pH}$ yaitu antara 6,8-9,6.
Kecerahan perairan menunjukan kemampuan sinar matahari yang masuk ke lapisan perairan pada kedalaman tertentu. Kedalaman disuatu perairan berhubungan dengan tingkat kecerahan dan akan mempengaruhi intensitas cahata matahari ke kolom perairan. Hasil pengamatan kecerahan di lokasi penelitian yaitu menunjukan nilai $100 \%$ dan kedalaman dilokasi penelitian berkiar 40-80 $\mathrm{cm}$ pada kondisi surut dan pada saat pasang berkisar 1-3 m. Abdan dan Ruslaini (2013) menyatakan bahwa kecerahan perairan yang tidak keruh dengan kisaran kecerahan $100 \%$ baik untuk pertumbuhan rumput laut.

Hasil analisis pengukuran kadar nitrat pada awal penelitian kerang abalon $H$. squamata dan rumput laut Gracilaria sp. memiliki nilai yang sangat rendah yaitu $<0,01$. Kadar nitrat pada akhir penelitian menunjukan nilai nitrat sebesar 0,642 dan 0,711 mg/l. Keputusan Menteri Lingkungan Hidup (2004) menetapkan standar baku mutu senyawa nitrat untuk biota laut sebesar $0,008 \mathrm{mg} / \mathrm{l}$.

Kadar fosfat pada awal penelitian memiliki nilai fosfat $0,212 \mathrm{mg} / \mathrm{l}$ dan $0,611 \mathrm{mg} / \mathrm{l}$. Hasil analisis fosfat menunjukan bahwa kadar fosfat di lokasi penelitian memiliki nilai yang lebih tinggi dari baku mutu. Baku mutu untuk kehidupan biota laut untuk konsentasi fosfat yang layak dalam Keputusan Menteri Lingkungan Hidup, KLH (2004) adalah 0,015 mg/l. Kandungan fosfat pada akhir penelitian memiliki nilai 0,054 dan 0,1524 $\mathrm{mg} / \mathrm{l}$.

Secara umum kisaran nilai parameter lingkungan pada lokasi penelitian masih dapat ditoleril untuk pertumbuhan kerang abalon dan rumput laut, sehingga dapat dikatakan sesuai untuk dilakukannya budidaya kerang abalon $H$. squamata bersama rumput laut Gracilaria sp.

\subsection{Laju Pertumbuhan Spesifik (SGR)}

Berdasarkan hasil pengukuran berat badan kerang abalon yang dilakukan setiap 15 hari sekali selama 45 hari budidaya dan diperoleh rata-rata laju pertumbuhan spesifik. Hasil rata-rata laju pertumbuhan spesifik yang dipelihara pada sistem budidaya IMTA dan sistem monokultur disajikan pada Gambar 3.

Laju pertumbuhan spesifik (SGR) kerang abalon pada hari ke-15 untuk perlakuan T2 yang diintegrasikan bersama rumput laut densitas 50 gram dan T3 yang diintegrasikaan dengan rumput laut 100 gram memiliki nilai pertumbuhan 


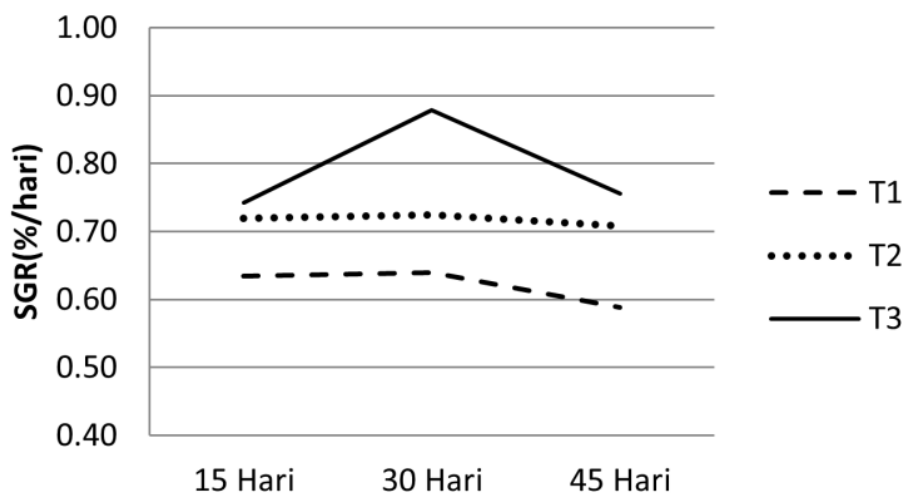

Gambar 3. Grafik Laju Pertumbuhan Spesifik (SGR) kerang abalon Haliotis squamata pada sistem budidaya IMTA dan sistem monokultur.

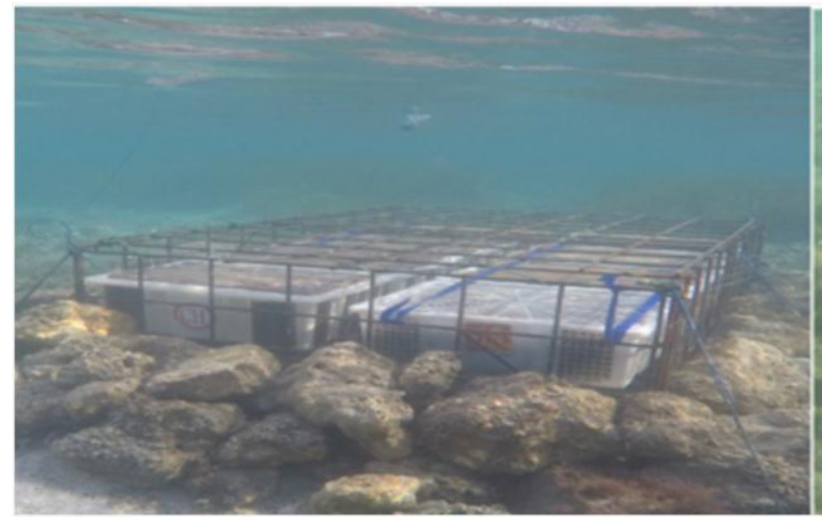

(a)

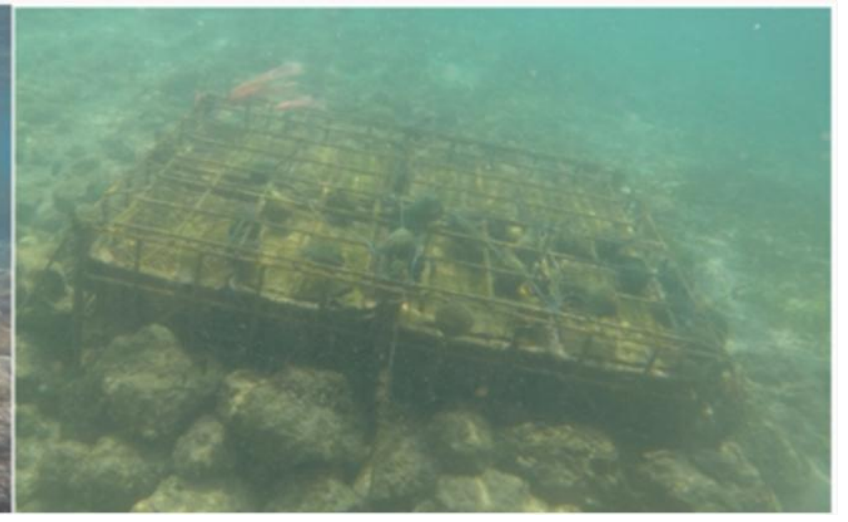

(b)

Gambar 4. (a) Kondisi keranjang kerang abalon sebelum diintegrasikan dengan rumput laut Gracilaria sp. (b) Kondisi keranjang kerang abalon setelah diintegrasikan dengan rumput laut Gracilaria sp.

tertinggi yaitu sebesar 0,72\%/hari dan $0,74 \%$ /hari dengan rerata berat awal yaitu 15.07 gram dan 13.30 gram. Perlakuan T1 sebagai kontrol memiliki nilai pertumbuhan paling rendah dengan nilai sebesar $0,63 \%$ dan rerata berat awal yaitu 14,61 gram.

Perlakuan T2 dan T3 pada sistem budidaya IMTA memiliki perbedaan nilai pertumbuhan berat badan kerang abalon yang signifikan berbeda. Perbedaan nilai tersebut diduga karena terdapat tambahan oksigen dari proses fotosintesis rumput laut Gracilari sp. tetapi pada perlakuan T3 lebih banyak mendapatkan masukan oksigen karena memiliki densitas rumput laut yang lebih tinggi yaitu 100 gram dibandingkan dengan densitas rumput laut 50 gram diperlakuan T2.

Tingginya laju pertumbuhan kerang abalon pada sistem budidaya IMTA disebabkan oleh pengintegrasian antara kerang abalon dan rumput laut, dimana rumput laut berfungsi sebagai biofilter yang menyaring sisa feses abalon berupa nutrient urea sehingga peranan dari rumput laut Gracilaria sp. dalam kerangka budidaya IMTA termanfaatkan dan memberikan keseimbangan ekosistem yang optimal di perairan. Nobre et al., (2010), menyatakan bahwa dalam kerangka budidaya IMTA, kerang abalon dan rumput laut, telah menurunkan kadar nitrogen $(\mathrm{N})$ dan fosfor (P) perairan sebesar $44 \%$ dan $23 \%$ dibandingkan dengan budidaya abalon secara monokultur. Kerang abalon berperan sebagai filter feeder dapat menyaring makanan atau memanfaatkan partikel tersuspensi berupa zat organik, sedangkan rumput laut Gracilaria sp. memiliki peranan sebagai biofilter dan akan memanfaatkan perairan yang kaya akan nutrien untuk pertumbuhannya. Pada 
perlakuan kontrol kerang abalon dipelihara pada sistem monokultur sehingga oksigen yang didapat lebih sedikit dibanding dengan sistem budidaya IMTA yaitu pada perlakuan budidaya IMTA.

Rumput laut merupakan salah satu tumbuhan akuatik yang dapat menyeimbangkan $\mathrm{O}_{2}$ didalam suatu perairan. Puspitaningrum et al., (2012), menyatakan bahwa tumbuhan akuatik merupakan faktor terpenting didalam ekosistem perairan untuk menentukan keseimbangan $\mathrm{O}_{2}$. Keadaan keranjang kerang abalon yang kurang bersih menyebabkan munculnya gulma disekitar keranjang kerang abalon (Gambar 4). Gulma tersebut diduga dapat menyebabkan terhambatnya laju proses fotosintesis pada rumput laut dan bersifat sebagai kompetitor.

Perbedaan nilai pertumbuhan berat badan kerang abalon pada hari ke-15 ditiap perlakuan belum dapat dikatakan terjadinya kenaikan pertumbuhan yang optimal, dikarenakan kerang abalon memiliki pertumbuhan yang lambat dan membutuhkan waktu pemeliharaan yang lebih lama untuk mencapai ukuran yang optimal. Hal ini sesuai dengan pendapat Stickney (2000) in Susanto et al., (2010) kerang abalon termasuk hewan yang memiliki pertumbuhan yang lambat. Berdasarkan hasil uji statistik ANOVA berat kerang abalon $H$. squamata bahwa nilai signifikansi $<\alpha=0.05$ sehingga pertumbuhan pada hari ke15 menyebabkan perbedaan berat badan kerang abalon.

Laju pertumbuhan spesifik kerang abalon $H$. squamata pada hari ke-30 bahwa pada perlakuan T2 dan perlakuan T3 yang diintegrasikan dengan rumput laut 50 gram dn 100 gram tetap menunjukan hasil yang lebih tinggi ketimbang dengan perlakuan T1 sebagai kontrol. Akan tetapi, terdapat sedikit perbedaan hasil pada perlakuan T2 dan T3, dimana hasil yang lebih baik terdapat pada perlakuan T3 yang diintegrasikan dengan rumput laut 100 gram. Hal ini dapat dilihat bahwa pertumbuhan dengan sistem budidaya IMTA memiliki hasil yang lebih tinggi yaitu dengan nilai $0,73 \% /$ hari $-0,88 \%$ /hari dan perlakuan $\mathrm{T} 1$ sebagai kontrol memiliki nilai yaitu $0,64 \%$ /hari.

Jumlah kerang abalon yang mulai berkurang pada wadah pemeliharaan menyebabkan kompetisi pakan menjadi lebih berkurang, sehingga padat penebaran mempengaruhi kebutuhan pakan kerang abalon. Berdasarkan hasil analisi uji statistik ANOVA berat badan kerang abalon $H$. squamata bahwa nilai signifikansi $>\alpha=0.05$ sehingga pertumbuhan bobot badan kerang abalon $H$. squamata pada hari ke-30 menunjukan berat badan kerang abalon yang sama dan berkurangnya padat penebaran tidak mempengaruhi pertumbuhan berat dihari ke-30.

Berdasarkan nilai SGR kerang abalon pada hari ke-45 menunujukan penurunan nilai terutama pada perlakuan T3 yang diintegrasikan bersama rumput laut dengan densitas 100 gram, akan tetapi perlakuan T3 memiliki nilai pertumbuhan yang tertinggi sebesar 0,76\%. Sedangkan pada perlakuan T2 yang diintegrasikan bersama rumput laut dengan densitas 50 gram dan perlakuan T1 sebagai kontrol memiliki nilai pertumbuhan sebesar 0,71\%/hari dan 0,59\%/hari. Hal ini disebabkan oleh faktor eksternal yaitu, mulai terjadinya pencemaran pada lingkungan perairan akibat adanya tumpahan minyak yang diduga berasal dari bahan bakar perahu nelayan, selain itu terdapat limbah anorganik seperti sampah plastik, dan adanya faktor perubahan cuaca yaitu terjadinya hujan.

Faktor tersebut diduga menyebabkan penurunan pertumbuhan berat kerang abalon, dapat dilihat dari semua perlakuan, tidak hanya dari perlakuan yang diintegrasikan dengan

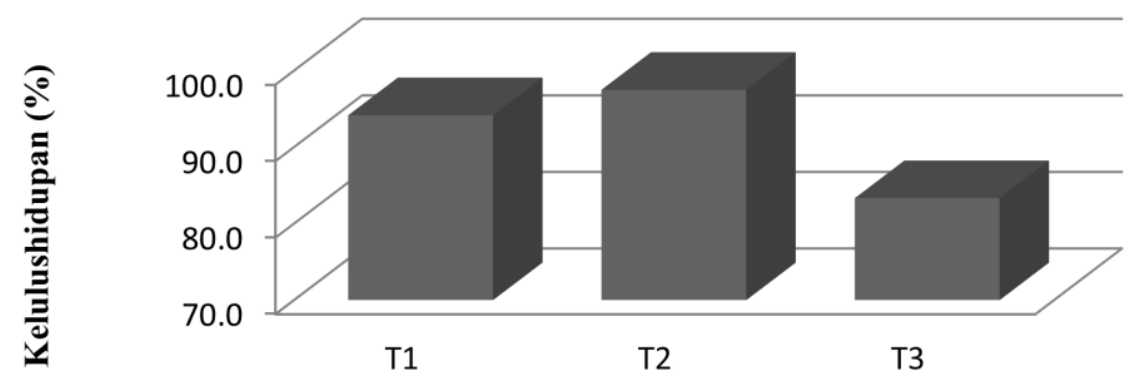

Perlakuan

Gambar 6. Kelulushidupan kerang abalon Haliotis squamata pada sistem budidaya IMTA dan monokultur. 
rumput laut tetapi pada perlakuan kontrol juga mengalami penurunan pertumbuhan berat. Penurunan pertumbuhan berat pada hari ke-45 diduga tidak disebabkan oleh keberadaan rumput laut akan tetapi karena kondisi perairan dan faktor perubahan cuaca.

Berdasarkan pernayataan Rejeki et al., (2014) bahwa lingkungan juga sangat berperan dalam pertumbuhan kerang abalon. Berdasarkan hasil analisis uji statistik ANOVA berat badan kerang abalon $H$. squamata pada sistem budidaya terintegrasi dan sistem budidaya secara monokultur dapat diketahui nilai signifikansi $<\alpha=0.05$ sehingga pertumbuhan berat badan kerang abalon pada hari ke-45 berbeda nyata atau adanya perbedaan berat badan kerang abalon.

\subsection{Kelulushidupan}

Berdasarkan hasil kelulushidupan kerang abalon H. squamata yang dibudidayakan secara budidaya monokultur dan budidaya IMTA pada akhir penelitian menunjukan nilai rata-rata kelulushidupan kerang abalon selama 45 hari pemeliharaan. Hasil kelulushidupan kerang abalon $H$. squamata disemua perlakuan pada budidaya monokultur dan IMTA disajikan pada Gambar 6.

Kelulushidupan kerang abalon dari grafik tersebut menunjukan bahwa nilai pada perlakuan T1 sebagai kontrol memiliki nilai kelulushidupan yaitu sebesar 94,5\% untuk perlakuan T2 yang diintegrasikan dengan rumput laut 50 gram memiliki nilai kelulushidupan yaitu sebesar 97,5\% dan perlakuan T3 yang diintegrasikan dengan rumput laut 100 gram memiliki nilai kelulushidupan yaitu sebesar 83,3\%.

Berdasarkan hasil kelulushidupan tersebut nilai tertinggi terdapat pada perlakuan T2 yang diintegrasikan dengan rumput laut 50 gram dan terendah pada perlakuan T3 yang diintegrasikan dengan rumput laut 100 gram. Jika dilihat dari konsep budidaya IMTA, kelulushidupan kerang abalon $H$. squamata menjadi lebih optimal dari pada sistem budidaya monokultur atau kontrol. Hal ini disebabkan karena adanya predator yang lebih mendominasi disekitar kontruksi perlakuan T3 yang diintegrasikan dengan rumput laut Gracilaria sp. seperti (ikan dan moluska) dan pengamatan pertumbuhan yang dilakukan dua minggu sekali dapat mengakibatkan terjadinya stres pada kerang abalon. Selama sampling pertumbuhan berat badan kerang abalon, dibutuhkan penanganan yang ekstra hati-hati karena kerang abalon sangat sensitif terhadap gesekan. Rejeki et al., (2014) mengemukakan bahwa, penanganan yang kurang hati-hati dapat menimbulkan stress dan pada kondisi ini kerang abalon sangat riskan terhadap serangan penyakit.

\section{Kesimpulan}

Berdasarkan hasil penelitian laju pertumbuhan kerang abalon Haliotis squamata melalui budidaya IMTA di Pantai Geger, Nusa Dua, Kabupaten Badung, Provinsi Bali, Pertumbuhan kerang abalon H. squamata pada perlakuan T3 yang diintegrasikan bersama rumput laut Gracilaria sp. dengan densitas 100 gram memiliki nilai pertumbuhan tertinggi yaitu sebesar $0,76 \%$, kemudian diikuti oleh perlakuan T2 yang diintegrasikan bersama rumput laut Gracilaria sp. dengan densitas 50 gram yaitu sebesar $0,71 \%$ dan nilai terendah terdapat pada budidaya secara monokultur dengan nilai pertumbuhan sebesar 0,59\%. Kelulushidupan tertinggi terdapat pada T2 yaitu sebesar 97,5\%, kemudian diikuti oleh perlakuan T1 sebagai kontrol yaitu sebesar 94,5\% dan nilai kelulushidupan terendah terdapat pada perlakuan T3 sebesar 83,3\%. Parameter kualitas perairan fisika dan kimia mendukung budidaya terintegrasi terhadap pertumbuhan kerang abalon H. squamata bersama dengan rumput laut Gracilaria sp. di Pantai Geger, Nusa Dua, Kabupaten Badung, Provinsi Bali.

\section{Ucapan Terima Kasih}

Penulis mengucapkan terima kasih kepada Bapak Simbik dan Bapak Made Kutir yang membantu dan memberikan fasilitas selama penelitian.

\section{Daftar Pustaka}

Abdan, A., Rahman, A., \& Ruslaini, R. (2013). Pengaruh Jarak Tanam Terdapat Pertumbuhan dan Kandungan Karagenan Rumput Laut (Eucheuma spinosum) Menggunakan Metode Long Line. Jurnal Mina Laut Indonesia, 3(12), 113-123.

Ain, N., Ruswahyuni, R., \& Widyotrini, N. (2014). Hubungan Kerapatan Rumput Laut dengan Substrat Dasar Berbeda di Perairan Pantai Bandengan, Jepara. Management of Aquatic Resources Journal, 2(4), 118-126.

Aliah, R. S. (2012). Keragaman Model Budidaya Perikanan Terintegrasi Multi Tropik di Pantai Utara 
Karawang, Jawa Barat. Jurnal Teknologi Lingkungan, 13(1), 47-58.

Cook, P. A., \& Gordon H. R. (2010). World Abalone Supply, Markets, and Pricing. Journal of Shellfish Research, 29(3), 569-571.

Dahlia, I., Rejeki, S., \& Susilowati, T. (2015). Pengaruh Dosis Pupuk dan Substrat yang Berbeda Terhadap Pertumbuhan Caulerpa lentillifera. Journal of Aquaculture Management and Technology, 4(4), 28-34.

Effendi, H. (2003). Telaah Kualitas Air: Bagi Pengolahan Sumberdaya dan Lingkungan Perairan. Yoyakarta, Indonesia: Kanisius.

Gordon, H. R., \& Cook, P. A. (2013). World abalone supply, markets, and pricing: 2011 update. Journal of Shellfish Research, 32(1), 5-7.

Guo, H., Yao, J., Sun, Z., \& Duan, D. (2014). Effect of Temperature, Irradiance on the Growth of the Green Alga Caulerpa lentillifera (Bropsidophyceae, Chrolophyta). Journal of Applied Phycoligy, 27(2), 879885.

Mudeng, J. D., Kolopita, M. E. F., \& Rahman, A. (2015). Kondisi Lingkungan Perairan Pada Lahan Budidaya Rumput Laut Kappaphycus alvarezii di Desa Jayakarsa Kabupaten Minahasa Utara. Jurnal Budidaya Perairan, 3(1), 172-186.

Nobre, A. M., Robertson-Andersson, D., Neori, A., \& Sankar, K. (2010). Ecological-economic assessment of aquaculture options: Comparison between abalone monoculture and integrated multi-trophic aquaculture of abalone and seaweed. Aquaculture, 306(1), 116-126.

Nurfajrie, N., Suminto, S., \& Rejeki, S. (2014). Pemanfaatan Berbagai Jenis Makroalga Untuk Pertumbuhan Abalon (Haliotis squamata) Dalam Budidaya Pembesaran. Journal of Aquaculture Management and Technology, 3(4), 142-150.

KLH. (2004). Baku mutu air laut untuk biota laut. Keputusan Menteri Negara Lingkungan Hidup No.51 Tahun 2004 Tentang Baku Mutu Air Laut. Jakarta., Indonesia: Kementerian Lingkungan Hidup Republik Indonesia.
Leighton, D. I. (2008). Abalone Hatchery Manual. Dublin, Ireland: Aquaculture Technical Section, Aquaculture Development Division. Co.

Puspitaningrum, M., Izzati, M., \& Haryanti, S. (2012). Produksi dan Konsumsi Oksigen Terlarut oleh Beberapa Tumbuhan Air. Buletin Anatomi Dan Fisiologi dh Sellula, 12(1), 47-55.

Ren, J. S., Stenton-Dozey, J., Plew, D. R., Fang, J., \& Gall, M. (2012). An ecosystem model for optimizing production in integrated multitrophic aquaculture system. Ecological Modelling, 246, 34-46.

Rejeki, S., Humaidi, H., \& Ariyati, R. W. (2014). Pembesaran Siput Abalon (Haliotis squamata) Dalam Keramba Tancap di Area Pasang Surut Dengan Padat Tebar Yang Berbeda. Journal of Aquaculture Management and Technology, 3(4), 214-221.

Setyono D. E. D. (2004). Abalone (Haliotis asinina L): 3. induction of spawning. Oseana, 29 (3), 17-23.

Setyowati, D. N. A., Diniarti, N., \& Waspodo, S. (2013). Budidaya Lobster (Panulirus homarus) dan Abalon (Haliotis sp.) Dengan Sistem Integrasi di Perairan Teluk Ekas. Jurnal Kelautan: Indonesian Journal of Marine Science and Technology, 6(2), 137-141.

Soelistyowati, D. T., Kusumawardhani, A., \& Junior, M. Z. (2013). Karakteristik Fenotipe Benih Hidrida Interspesifik Abalon Haliotis asinina dan Haliotis squamata. Jurnal Akuakultur Indonesia, 12(1), 25-30.

Susanto, B., Rusdi, I., Ismi, S., \& Rahmawati, R. (2010). Pemeliharaan yuwana abalon (Haliotis squamata) Turunan F-1 Secara Terkontrol Dengan Jenis Pakan Berbeda. Jurnal Riset Akuakultur, 5(2), 199-209.

Syahlun, S., Rahman, A., \& Ruslaini, R. (2011). Uji Pertumbuhan Rumput laut Kappaphycus alvarezii. Strain Coklat dengan Metode Vertikulur. Jurnal Mina Laut Indonesia, 1(1), 122-132.

Yustianti, Y., Ibrahim, M. N., \& Ruslaini, R. (2011). Pertumbuhan dan Sintasan Larva Udang Vaname (Litopenaeus vannamei) Melalui Substitusi Tepung Ikan dengan Tepung Usus Ayam. Jurnal Mina Laut Indonesia, 1(1), 93-103

(C) 2017 by the authors; licensee Udayana University, Indonesia. This article is an open access article distributed under the terms and conditions of the Creative Commons Attribution license (http://creativecommons.org/licenses/by/3.0/). 